BMJ Open Diabetes Research $\&$ Care

\section{Correlation between markers of renal function and sight-threatening diabetic retinopathy in type 2 diabetes: a longitudinal study in an Indian clinic population}

To cite: Rajalakshmi R, Shanthi Rani CS, Venkatesan U, et al. Correlation between markers of renal function and sight-threatening diabetic retinopathy in type 2 diabetes: a longitudinal study in an Indian clinic population. BMJ Open Diab Res Care 2020;8:e001325. doi:10.1136/ bmjdrc-2020-001325

\section{- Additional material is} published online only. To view please visit the journal online (http://dx.doi.org/10.1136/ bmjdrc-2020-001325).

Received 29 February 2020 Revised 11 April 2020 Accepted 28 April 2020
Check for updates

\section{(C) Author(s) (or their} employer(s)) 2020. Re-use permitted under CC BY-NC. No commercial re-use. See rights and permissions. Published by BMJ.

For numbered affiliations see end of article.

Correspondence to Dr Viswanathan Mohan; drmohans@diabetes.ind.in

\section{ABSTRACT}

Introduction Previous epidemiological studies have reported on the prevalence of diabetic kidney disease (DKD) and diabetic retinopathy (DR) from India. The aim of this study is to evaluate the effect of DKD on the development of new-onset DR and sight-threatening diabetic retinopathy (STDR) in Asian Indians with type 2 diabetes (T2D).

Research design and methods The study was done on anonymized electronic medical record data of people with T2D who had undergone screening for DR and renal work-up as part of routine follow-up at a tertiary care diabetes center in Chennai, South India. The baseline data retrieved included clinical and biochemical parameters including renal profiles (serum creatinine, estimated glomerular filtration rate (eGFR) and albuminuria). Grading of DR was performed using the modified Early Treatment Diabetic Retinopathy Study grading system. STDR was defined as the presence of proliferative diabetic retinopathy (PDR) and/or diabetic macular edema. DKD was defined by the presence of albuminuria ( $\geq 30 \mu \mathrm{g} / \mathrm{mg}$ ) and/or reduction in eGFR $\left(<60 \mathrm{~mL} / \mathrm{min} / 1.73 \mathrm{~m}^{2}\right)$. Cox regression analysis was used to evaluate the hazard ratio (HR) for DR and STDR.

Results Data of 19909 individuals with T2D (mean age $59.6 \pm 10.2$ years, mean duration of diabetes $11.1 \pm 12.1$ years, $66.1 \%$ male) were analyzed. At baseline, DR was present in 7818 individuals (39.3\%), of whom 2249 $(11.3 \%)$ had STDR. During the mean follow-up period of $3.9 \pm 1.9$ years, $2140(17.7 \%)$ developed new-onset DR and 980 individuals with non-proliferative DR (NPDR) at baseline progressed to STDR. Higher serum creatinine (HR 1.5, 95\% Cl 1.3 to 1.7; $\mathrm{p}<0.0001$ ), eGFR $<30 \mathrm{~mL} /$ $\mathrm{min} / 1.73 \mathrm{~m}^{2}$ (HR $4.9,95 \% \mathrm{Cl} 2.9$ to $8.2 ; \mathrm{p}<0.0001$ ) and presence of macroalbuminuria $>300 \mu \mathrm{g} / \mathrm{mg}$ (HR $3.0,95 \% \mathrm{Cl} 2.4$ to $3.8 ; \mathrm{p}<0.0001$ ) at baseline were associated with increased risk of progression to STDR. Conclusions DKD at baseline is a risk factor for progression to STDR. Physicians should promptly refer their patients with DKD to ophthalmologists for timely detection and management of STDR.

\section{Significance of this study}

What is already known about this subject?

- The prevalence of and risk factors for diabetic kidney disease (DKD) and diabetic retinopathy (DR) have been assessed in previous epidemiological studies from India.

What are the new findings?

- DKD at baseline is an important risk factor for progression to sight-threatening diabetic retinopathy (STDR).

- This is the first longitudinal study on a large sample from India that has provided a detailed analysis of the two important markers of renal function, estimated glomerular filtration rate (eGFR) and albuminuria, and the association of DKD with the development of new-onset DR and progression to STDR in Asian Indians with type 2 diabetes.

How might these results change the focus of research or clinical practice?

- The eGFR values can be used by physicians for monitoring patients to enable timely referral to ophthalmologists for prompt management of STDR.

\section{INTRODUCTION}

The escalating prevalence of diabetes in India, which is already home to over 77 million people with diabetes, ${ }^{12}$ is also likely to herald an increase in the complications of diabetes in the country. ${ }^{3-6}$ Diabetic retinopathy (DR) and diabetic nephropathy (DN) (now called diabetic kidney disease (DKD)) are the most common microvascular complications of diabetes. DR and DKD are major causes of social and economic burden to individuals with diabetes and the healthcare system due to the risk of blindness ${ }^{7}$ and end-stage 
renal disease. ${ }^{4}$ These microvascular complications have common risk factors, such as long duration of diabetes, poor glycemic control and hypertension. ${ }^{589}$

Proliferative diabetic retinopathy (PDR) and diabetic macular edema (DME) are the main sight-threatening forms of DR (STDR). There have been some clinic-based as well as population-based studies published on the prevalence of DR and DKD/microalbuminuria in India. ${ }^{3-6}$ Earlier studies done globally as well as in India have shown an association between albuminuria and DR, in both type 1 and type 2 diabetes. ${ }^{58-13}$ In a meta-analysis of 26 studies done in 2013 to assess if DR could predict $\mathrm{DN}$, it was found that PDR was a more specific predictor of DN. ${ }^{14}$ Conversely, it would be useful to know if the presence of DKD would help in predicting progression to STDR because regular retinal photographic screening for STDR in every person with diabetes in India is challenging. Urine albumin to creatinine ratio (UACR) and estimated glomerular filtration rate (eGFR), the most widely used markers of renal function, ${ }^{15}{ }^{16}$ are probably easier to perform in this population as compared with regular screening retinal examination.

There have been no studies from India that have looked at the association between DKD and the incidence of STDR. Hence, in this study we investigated the association between DKD and the development of STDR in Asian Indians with type 2 diabetes (T2D).

\section{METHODS AND STUDY DESIGN}

Participants in this study are individuals with T2D who are under regular care at a tertiary care center for diabetes in Chennai, South India. The center has a Diabetes Electronic Medical Records (DEMR) system incorporating the complete details of several thousand patients with diabetes, each of whom has a unique identification number such that any given patient has only one record with multiple follow-up visits documented in the same record.

From our DEMR data, we identified 19909 individuals with T2D who had undergone routine screening for assessment of DR and DKD during the same visit in the year 2011 and had subsequently been followed up regularly every 3-6 months between 2011 and 2018. Only those who had provided written informed consent to use their anonymized medical data were included in the study.

\section{Data collection}

The clinical protocol included elicitation of detailed medical history, including age of onset of diabetes, duration of diabetes, treatment history (systemic medications), family history of diabetes, history of hypertension and assessment of diet and physical activity. Diabetes was diagnosed if the fasting plasma glucose (FPG) level was $\geq 126 \mathrm{mg} / \mathrm{dL}(7.0 \mathrm{mmol} / \mathrm{L})$ and $/$ or the 2-hour postload glucose level was $\geq 200 \mathrm{mg} / \mathrm{dL}(11.1 \mathrm{mmol} / \mathrm{L})$ and/or if the patient had been prescribed pharmacotherapy for diabetes by a physician. ${ }^{17}$ T2D was diagnosed by absence of ketosis, good beta-cell reserve as shown by fasting $\mathrm{C}$ peptide assay $(>0.6 \mathrm{pmol} / \mathrm{mL})$, absence of pancreatic calculi on abdominal radiograph, and response to oral hypoglycemic agents (OHA) alone for at least 2 years. ${ }^{12}$ Hypertension was defined as a self-reported history of physician-diagnosed hypertension or if the participants were on medications for hypertension, or had a systolic blood pressure of $\geq 140 \mathrm{~mm} \mathrm{Hg}$ and/or diastolic blood pressure of $\geq 90 \mathrm{~mm} \mathrm{Hg}$. ${ }^{18}$

During annual visits to the center, the patients underwent the following assessments: height, weight and waist circumference were measured and body mass index (BMI) was calculated as the ratio of the weight in kilograms to the square of height in meters. Blood pressure was measured using standardized techniques. Assessment of baseline biochemical parameters included FPG, glycated hemoglobin (HbA1c), serum lipid profile and renal profile (blood urea, serum creatinine, microalbuminuria and eGFR). Our laboratory is certified by the College of American Pathologists as well as the National Accreditation Board for Testing and Calibration Laboratories.

Plasma glucose (hexokinase method), serum cholesterol (cholesterol oxidase-peroxidase-amidopyrine method), triglycerides (glycerol phosphate oxidaseperoxidase-amidopyrine method), high-density lipoprotein cholesterol (direct method-polyethylene glycol-pretreated enzymes), blood urea (Glutamate dehydrogenase (GLDH) UV kinetic method) and serum creatinine (Jaffe kinetic method) were measured on Beckman Coulter AU2700 (Fullerton, California, USA) biochemistry analyzer. ${ }^{19}$ Low-density lipoprotein cholesterol was calculated using the Friedewald formula. HbAlc was estimated by high-performance liquid chromatography using the Variant machine (Bio-Rad, Hercules, California, USA). Urinary albumin concentration was measured in a fasting urine sample using an immunoturbidimetric assay (Beckman Coulter AU2700 biochemistry analyzer).

Comprehensive assessments for diabetic retinopathy and nephropathy were performed at baseline and during follow-up as described in the following sections.

\section{Diabetic retinopathy}

All patients underwent a complete ophthalmic examination that included visual acuity measurement, intraocular pressure measurement, slit lamp examination of the anterior segment, and fundus examination after dilatation using direct and indirect ophthalmoscopy performed by retina specialists. Digital retinal (fundus) color photography was performed using mydriatic conventional desktop fundus camera (Carl Zeiss, FF 450 Plus camera; Jena, Switzerland) after mydriasis. The modified Early Treatment Diabetic Retinopathy Study (ETDRS) grading system was used for grading of DR by retina specialists. ${ }^{20}$ DR was broadly classified as (1) level 10: no retinopathy; (2) levels 20-58: non-proliferative diabetic retinopathy (NPDR); (3) levels $\geq 60$ : PDR. Any-DR was defined by the presence of at least one definite microaneurysm in one or both eyes, and STDR was defined by the presence of 
PDR and/or DME. ${ }^{21}$ DME was defined as retinal thickening and/or presence of definite hard exudates at or within one disc diameter of the center of the macula. ${ }^{22}$

\section{Diabetic kidney disease}

DKD was defined as (1) eGFR less than $60 \mathrm{~mL} / \mathrm{min} / 1.73 \mathrm{~m}^{2}$ and/or (2) albuminuria $30 \mu \mathrm{g} / \mathrm{mg}$ or above. ${ }^{16}$ Renal failure is defined as eGFR $<30 \mathrm{~mL} / \mathrm{min} / 1.73 \mathrm{~m}^{2}$.

The Chronic Kidney Disease-Epidemiology Collaboration formula was used for calculation of eGFR. ${ }^{23}$ The eGFR level was expressed in $\mathrm{mL} / \mathrm{min} / 1.73 \mathrm{~m}^{2}$ and as per the Kidney Disease: Improving Global Outcomes (KDIGO) defined and graded into five levels ${ }^{16}$ : (1) normal: eGFR $>90 \mathrm{~mL} / \mathrm{min} / 1.73 \mathrm{~m}^{2}$; (2) mildly diminished: eGFR $60-89 \mathrm{~mL} / \mathrm{min} / 1.73 \mathrm{~m}^{2}$; (3) moderately diminished: eGFR $45-59 \mathrm{~mL} / \mathrm{min} / 1.73 \mathrm{~m}^{2}$; (4) moderate-severely diminished: eGFR $30-44 \mathrm{~mL} / \mathrm{min} / 1.73 \mathrm{~m}^{2}$; and (5) severely diminished: eGFR $<30 \mathrm{~mL} / \mathrm{min} / 1.73 \mathrm{~m}^{2}$. With respect to albuminuria, it was divided into three groups: (1) $<30 \mu \mathrm{g} / \mathrm{mg}$ (normoalbuminuria); (2) $\geq 30 \mu \mathrm{g} / \mathrm{mg}$ to $<300 \mu \mathrm{g} / \mathrm{mg}$ (microalbuminuria); and (3) $\geq 300 \mu \mathrm{g} / \mathrm{mg}$ (macroalbuminuria).$^{5}$

\section{Statistical analysis}

All statistical analyses were performed using SAS V.9.4. Continuous data are expressed as mean $\pm \mathrm{SD}$, while categorical data are presented as proportions. To compare characteristics between the two groups, independent t-test and $\chi^{2}$ test were used to compare means and proportions, respectively. To compare characteristics between the no DR, NPDR and PDR groups, analysis of variance was used. Calculation of the incidence of DR and other complications was done as follows: for calculation of the incidence of DR, people with no DR at baseline were included. For calculation of the incidence of STDR, those who had STDR at baseline were excluded. Only those who had no DR or NPDR at baseline and progressed to develop STDR during the follow-up were included in the STDR incidence calculation. Person-years for each complication was calculated from the baseline examination until the event developed or death occurred or until the last examination, whichever came first. Incidence of complications with $95 \%$ CI was calculated per 1000 person-years with the number of persons who developed complication during follow-up as numerator and the total person-time as denominator. For those without DR/STDR at baseline, Cox regression model was used to calculate the Hazard Ratio (HR) for the renal profiles for any new-onset DR and new-onset STDR after adjusting for covariates. Survival analysis was carried out using the Kaplan-Meier curve.

For all statistical tests, $p$ value of $<0.05$ was considered statistically significant.

\section{RESULTS}

A total of 19909 individuals with T2D met the inclusion criteria. Two-thirds $(66.1 \%)$ of the participants were male. The mean age of the cohort was $59.6 \pm 10.2$ years and the mean duration of diabetes was $11.1 \pm 12.1$ years (table 1). Any-DR was present in 7818 (39.3\%) and STDR was present in $2249(11.3 \%)$ patients at baseline. NPDR was present in 7381 (37.1\%) patients, 437 (2.2\%) had PDR, and $2082(10.5 \%)$ had DME. The mean age of patients with any-DR was $61.3 \pm 9.5$ years, the mean duration of diabetes was $13.8 \pm 7.4$ years, the mean HbA1c was $8.8 \% \pm 1.9 \%$, and $2662(13.4 \%)$ patients had microalbuminuria and $1062(5.3 \%)$ individuals had eGFR $<60 \mathrm{~mL} /$ $\min / 1.73 \mathrm{~m}^{2}$ at baseline.

Table 1 shows the comparison of the baseline characteristics including renal profiles of patients with no DR, NPDR and PDR. Patients with NPDR as well as PDR were older, had had diabetes for a longer duration, and had lower BMI, higher FPG, higher HbAlc, higher systolic blood pressure, higher serum creatinine, lower eGFR and higher levels of albuminuria, than those without DR $(p<0.001)$. Over $75 \%$ of patients with PDR were on insulin (in addition to OHA) for management of diabetes as compared with only $20 \%$ of those without DR $(p<0.001)$.

Online supplementary table 1 compares the baseline characteristics including renal parameters of patients with no STDR and with STDR. Patients with STDR had higher serum creatinine, more significant albuminuria and lower eGFR levels compared with those without STDR $(\mathrm{p}<0.001)$.

The mean follow-up period of the study cohort was $3.9 \pm 1.9$ years (minimum follow-up was 1.5 years; maximum follow-up period was 7.9 years). The overall mean HbAlc at baseline for the 19909 individuals was $8.4 \% \pm 1.9 \%$, while at the end of follow-up it was $7.9 \pm 1.7 \%$. While $33.5 \%$ of the individuals with T2D were on both OHA and insulin (table 1) at baseline, at the end of the follow-up $42.9 \%$ of them were on both OHA and insulin for diabetic control $(\mathrm{p}<0.001)$.

The flow chart depicting the study and follow-up is shown in figure 1 .

\section{New-onset DR}

Of the 12091 patients with T2D with no DR at baseline, $2140(17.7 \%)$ developed DR during follow-up (table 2). The time to development of new-onset DR was $3.0 \pm 1.7$ years. Those with no DR at baseline progressed to mild or moderate NPDR and none of them developed STDR during the follow-up.

Table 3 shows the results of the Cox regression analysis of the relationship of renal biomarkers with the risk for development of new-onset DR after adjustment of all covariates. Higher baseline serum creatinine correlated with development of DR with an HR of 1.67 (95\% CI 1.33 to 2.09, $\mathrm{p}<0.001)$. Patients with eGFR $<60 \mathrm{~mL} / \mathrm{min} / 1.73 \mathrm{~m}^{2}$ had a significantly higher risk for new-onset $\mathrm{DR}$ as compared with those with an eGFR of $>90 \mathrm{~mL} / \mathrm{min} / 1.73 \mathrm{~m}^{2}$ (eGFR 46-60: HR 1.43, $\mathrm{p}=0.008$; eGFR 30-45: HR 2.04, $\mathrm{p}=0.009$ ). The HR increased to 3.93 for eGFR $<30 \mathrm{~mL} / \mathrm{min} / 1.73 \mathrm{~m}^{2}$ $(\mathrm{p}=0.002)$. The presence of microalbuminuria at baseline increased the HR for DR to 1.3 times $(95 \%$ CI 1.2 to 1.5 , $\mathrm{p}<0.001$ ), while macroalbuminuria increased the hazards 
Table 1 Clinical and biochemical characteristics of individuals with type 2 diabetes classified by diabetic retinopathy severity (at baseline)

\begin{tabular}{|c|c|c|c|c|c|}
\hline Variables & Overall (n=19 909) & No DR $(n=12$ 091) & NPDR $(n=7381)$ & PDR $(n=437)$ & $P$ value \\
\hline Male, n (\%) & $13151(66.1)$ & 7599 (62.8) & 5229 (70.8) & 323 (73.9) & $<0.001$ \\
\hline Age (years) & $59.6 \pm 10.2$ & $58.4 \pm 10.5$ & $61.3 \pm 9.6$ & $62.1 \pm 8.7$ & $<0.001$ \\
\hline Age at onset of DM (years) & $43.5 \pm 9.1$ & $44.8 \pm 9.2$ & $41.5 \pm 8.5$ & $40.2 \pm 8.3$ & $<0.001$ \\
\hline Duration of DM (years) & $11.1 \pm 12.1$ & $9.3 \pm 14.1$ & $13.7 \pm 7.4$ & $16.1 \pm 7.0$ & $<0.001$ \\
\hline Systolic blood pressure $(\mathrm{mm} \mathrm{Hg})$ & $129.7 \pm 16.8$ & $128.3 \pm 16.1$ & $131.7 \pm 17.2$ & $136.3 \pm 19.6$ & $<0.001$ \\
\hline Diastolic blood pressure $(\mathrm{mm} \mathrm{Hg})$ & $79.3 \pm 9.6$ & $79.3 \pm 8.4$ & $79.3 \pm 11.2$ & $80.3 \pm 9.5$ & 0.104 \\
\hline Body mass index $\left(\mathrm{kg} / \mathrm{m}^{2}\right)$ & $26.9 \pm 4.2$ & $27.2 \pm 4.2$ & $26.5 \pm 4.1$ & $26.4 \pm 4.1$ & $<0.001$ \\
\hline Fasting plasma glucose (mg/dL) & $162.5 \pm 61.6$ & $156.4 \pm 57.0$ & $171.4 \pm 66.3$ & $181.2 \pm 76.1$ & $<0.001$ \\
\hline $\mathrm{HbA1c}(\%)$ & $8.4 \pm 1.9$ & $8.1 \pm 1.8$ & $8.8 \pm 1.9$ & $9.5 \pm 1.8$ & $<0.001$ \\
\hline Total cholesterol (mg/dL) & $165.2 \pm 41.9$ & $167.1 \pm 41.3$ & $161.9 \pm 42.4$ & $168.1 \pm 46.8$ & $<0.001$ \\
\hline Triglycerides (mg/dL) & $160.4 \pm 122.7$ & $162.3 \pm 128.8$ & $156.2 \pm 110.0$ & $176.7 \pm 146.7$ & $<0.001$ \\
\hline HDL cholesterol (mg/dL) & $39.8 \pm 8.9$ & $39.8 \pm 8.8$ & $39.8 \pm 9.2$ & $39.4 \pm 9.2$ & 0.639 \\
\hline LDL cholesterol & $94.2 \pm 34.0$ & $95.9 \pm 34.0$ & $91.4 \pm 33.8$ & $94.8 \pm 36.1$ & $<0.001$ \\
\hline Urea (mg/dL) & $24.0 \pm 8.6$ & $23.0 \pm 7.3$ & $25.3 \pm 9.7$ & $30.7 \pm 14.2$ & $<0.001$ \\
\hline Creatinine $(\mathrm{mg} / \mathrm{dL})$ & $0.81 \pm 0.27$ & $0.78 \pm 0.21$ & $0.85 \pm 0.32$ & $1.03 \pm 0.50$ & $<0.001$ \\
\hline $\begin{array}{l}\text { Number of individuals with eGFR }<60 \\
\mathrm{~mL} / \mathrm{min} / 1.73 \mathrm{~m}^{2}, \mathrm{n}(\%)\end{array}$ & $1062(5.3)$ & $401(3.3)$ & $572(7.7)$ & $89(20.4)$ & $<0.001$ \\
\hline $\begin{array}{l}\text { Number of individuals with } \\
\text { microalbuminuria, } \mathrm{n}(\%)\end{array}$ & $4784(24.0)$ & $2122(17.6)$ & 2385 (32.3) & $277(63.4)$ & $<0.001$ \\
\hline \multicolumn{6}{|l|}{ Diabetes treatment, $\mathrm{n}(\%)$} \\
\hline $\mathrm{OHA}$ alone & $12342(62.0)$ & $9149(75.7)$ & $3149(42.7)$ & $44(10.1)$ & $<0.001$ \\
\hline Insulin alone & $896(4.5)$ & $357(3.0)$ & $486(6.6)$ & $53(12.1)$ & \\
\hline Both $\mathrm{OHA}$ and insulin & $6671(33.5)$ & $2585(21.4)$ & $3746(50.8)$ & $340(77.8)$ & \\
\hline $\begin{array}{l}\text { Number of individuals on } \\
\text { antihypertensive treatment, } \mathrm{n}\end{array}$ & 10219 & 5769 & 4144 & 306 & \\
\hline $\begin{array}{l}\text { Angiotensin II receptor blockers, } \mathrm{n} \\
(\%)\end{array}$ & $6833(66.9)$ & $3764(65.2)$ & $2856(68.9)$ & $213(69.7)$ & $<0.001$ \\
\hline ACE inhibitors, $\mathrm{n}(\%)$ & $675(6.6)$ & $393(6.8)$ & $267(6.5)$ & $15(4.9)$ & 0.389 \\
\hline Beta blockers, n (\%) & $1342(13.1)$ & $800(13.9)$ & $503(12.1)$ & $39(12.7)$ & 0.159 \\
\hline Calcium channel blockers n (\%) & 1369 (13.4) & $812(14.1)$ & $518(12.5)$ & $39(12.7)$ & 0.167 \\
\hline
\end{tabular}

The statistically signficant $p$ values are in bold.

DM, diabetes mellitus; DR, diabetic retinopathy; eGFR, estimated glomerular filtration rate; HbA1c, glycated hemoglobin; HDL, highdensity lipoprotein; LDL, low-density lipoprotein; NPDR, non-proliferative diabetic retinopathy; OHA, oral hypoglycemic agent; PDR, proliferative diabetic retinopathy.

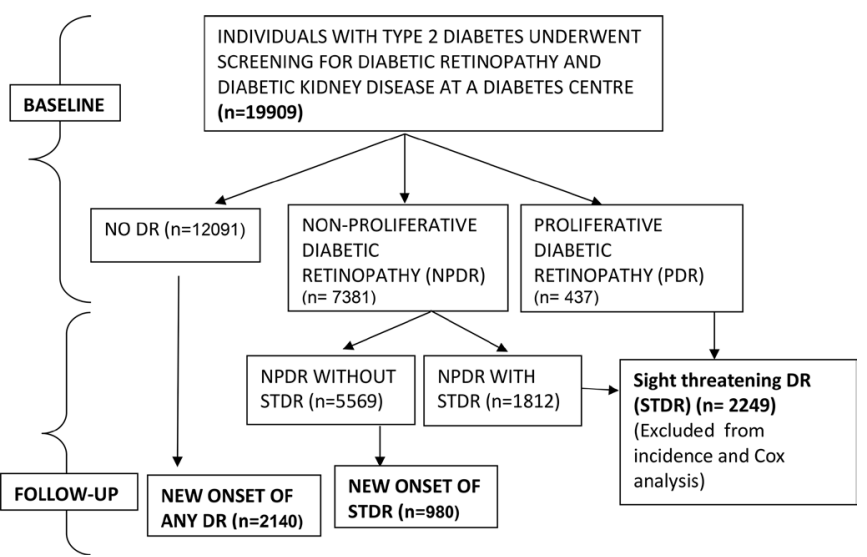

Figure 1 Flow chart depicting the longitudinal analysis of diabetic retinopathy (DR). for new-onset DR to two times $(\mathrm{p}<0.001)$ when compared with those with normoalbuminuria (table 3 ). When both albuminuria and reduced eGFR were included in the model, reduced eGFR $<30 \mathrm{~mL} / \mathrm{min} / 1.73 \mathrm{~m}^{2}$ showed a slight predomination over macroalbuminuria with respect to the risk for development of new-onset DR. There was no significant interaction between the two renal biomarkers, viz eGFR and albuminuria.

\section{New-onset STDR}

Among the 5569 individuals who had NPDR (mild/ moderate/severe NPDR) at baseline, 980 of them progressed to develop STDR (DME and/or PDR) during the follow-up (table 2). One hundred and fourteen individuals with NPDR at baseline progressed to PDR (2.0\%) 
Table 2 Incidence of diabetic retinopathy, sight-threatening diabetic retinopathy and diabetic kidney disease in the study cohort

\begin{tabular}{|c|c|c|c|c|}
\hline $\begin{array}{l}\text { Complications that } \\
\text { developed during follow-up }\end{array}$ & $\begin{array}{l}\text { People without the } \\
\text { complication (n) }\end{array}$ & $\begin{array}{l}\text { Person-years of } \\
\text { follow-up }\end{array}$ & $\begin{array}{l}\text { Outcomes, } \\
\text { n (\%) }\end{array}$ & $\begin{array}{l}\text { Rate per } 1000 \\
\text { person-years } \\
(95 \% \mathrm{Cl})\end{array}$ \\
\hline Any-DR & 12091 (no DR at baseline) & 37299 & $2140(17.7)$ & $\begin{array}{l}57.37 \\
\text { (54.97 to } 59.86)\end{array}$ \\
\hline STDR (DME and/or PDR) & $\begin{array}{l}5569 \text { (with NPDR and no STDR at } \\
\text { baseline) }\end{array}$ & 17369 & $\begin{array}{l}980(17.6) \\
\text { PDR: } 114(2.0) \\
\text { DME: } 866(15.6)\end{array}$ & $\begin{array}{l}56.42 \\
(52.94 \text { to } 60.07)\end{array}$ \\
\hline DKD & $\begin{array}{l}14709 \text { (with normal eGFR and without } \\
\text { microalbuminuria at baseline) }\end{array}$ & 46535 & $\begin{array}{l}2071 \\
(14.1)\end{array}$ & $\begin{array}{l}44.5 \\
\text { (42.61 to } 46.46)\end{array}$ \\
\hline
\end{tabular}

DKD, diabetic kidney disease; DME, diabetic macular edema; DR, diabetic retinopathy; eGFR, estimated glomerular filtration rate; NPDR, non-proliferative diabetic retinopathy; PDR, proliferative diabetic retinopathy; STDR, sight-threatening diabetic retinopathy.

and 866 progressed to develop DME (15.6\%) during the follow-up. The time to progression to new-onset STDR was $2.6 \pm 1.6$ years.

Higher serum creatinine (HR $1.49,95 \%$ CI 1.31 to 1.70 ; $\mathrm{p}<0.0001$ ), diminished eGFR (especially eGFR $<30 \mathrm{~mL}$ / $\min / 1.73 \mathrm{~m}^{2}$; HR $4.85,95 \%$ CI 2.87 to $8.21 ; \mathrm{p}<0.0001$ ), and presence of microalbuminuria $>30 \mu \mathrm{g} / \mathrm{mg}$ (HR 1.72, $95 \%$ CI 1.49 to $1.99 ; \mathrm{p}<0.0001)$ or macroalbuminuria $>300 \mu \mathrm{g} / \mathrm{mg}$ (HR 3.00, 95\% CI 2.41 to 3.75; p<0.0001) at baseline were associated with higher risk of progression to STDR after adjusting for all systemic covariates, as shown in table 3. Compared with individuals with T2D who had an eGFR of $>90 \mathrm{~mL} / \mathrm{min} / 1.73 \mathrm{~m}^{2}$, patients with eGFR $<60 \mathrm{~mL} / \mathrm{min} / 1.73 \mathrm{~m}^{2}$ had a significantly higher risk for progression to STDR (eGFR 46-60: HR 1.68, $\mathrm{p}=0.0015$; eGFR 30-45: HR 1.85, $\mathrm{p}=0.0129$; eGFR $<30$ : HR 4.85, p<0.0001) (table 3).

Figure 2 shows the Kaplan-Meier survival plots for newonset STDR in people with albuminuria $\geq 300 \mu \mathrm{g} / \mathrm{mg}$ and
eGFR $<30 \mathrm{~mL} / \mathrm{min} / 1.73 \mathrm{~m}^{2}$. Using the plots risk function, we observed that UACR $\geq 300 \mu \mathrm{g} / \mathrm{mg}$ significantly increased the cumulative risk of progression to STDR along with increase in the duration of diabetes, while eGFR did not show a significant correlation on the risk plot.

\section{Incidence of DKD}

Among the 14709 individuals who had normal eGFR and did not have microalbuminuria at baseline, 2071 (14.1\%) developed DKD during the follow-up. The cumulative incidence of DR, STDR and DKD during follow-up in this cohort is shown in table 2.

\section{DISCUSSION}

In this longitudinal analysis of a large number of patients with T2D undergoing care at a tertiary diabetes care center in South India, we report on the incidence of DR,

\begin{tabular}{|c|c|c|c|c|}
\hline Variables & $\begin{array}{l}\text { New-onset DR } \\
\text { HR (95\% Cl) }\end{array}$ & $P$ value & $\begin{array}{l}\text { STDR } \\
\text { HR }(95 \% \mathrm{Cl})\end{array}$ & $P$ value \\
\hline \multicolumn{5}{|l|}{ Baseline renal biomarkers } \\
\hline Serum creatinine & 1.67 (1.33 to 2.09$)$ & $<0.0001$ & 1.49 (1.31 to 1.70$)$ & $<0.0001$ \\
\hline \multicolumn{5}{|l|}{ eGFR $\left(\mathrm{mL} / \mathrm{min} / 1.73 \mathrm{~m}^{2}\right)$} \\
\hline$>90$ (normal) & 1 (reference) & NA & 1 (reference) & NA \\
\hline 61-90 (mildly diminished) & 1.01 (0.90 to 1.13$)$ & 0.8865 & 1.16 (0.99 to 1.37$)$ & 0.0640 \\
\hline 46-60 (moderately diminished) & $1.43(1.10$ to 1.87$)$ & 0.0081 & 1.68 (1.22 to 2.31$)$ & 0.0015 \\
\hline 30-45 (moderate-severely diminished) & 2.04 (1.34 to 3.10$)$ & 0.0009 & 1.85 (1.14 to 2.99$)$ & 0.0129 \\
\hline$<30$ (severely diminished) & 3.93 (1.63 to 9.48$)$ & 0.0023 & 4.85 (2.87 to 8.21$)$ & $<0.0001$ \\
\hline \multicolumn{5}{|l|}{ Albuminuria } \\
\hline Normoalbuminuria & 1 (reference) & NA & 1 (reference) & NA \\
\hline Microalbuminuria $(\geq 30 \mu \mathrm{g}$ to $<300 \mu \mathrm{g} / \mathrm{mg}$ ) & 1.34 (1.20 to 1.50$)$ & $<0.0001$ & 1.72 (1.49 to 1.99$)$ & $<0.0001$ \\
\hline Macroalbuminuria ( $\geq 300 \mu \mathrm{g} / \mathrm{mg}$ ) & 2.00 (1.57 to 2.55$)$ & $<0.0001$ & 3.00 (2.41 to 3.75$)$ & $<0.0001$ \\
\hline
\end{tabular}

The statistically signficant $\mathrm{p}$ values are in bold.

${ }^{*}$ The model is adjusted for age, gender, body mass index, systolic blood pressure, fasting blood sugar, glycated hemoglobin, duration of diabetes, cholesterol, triglyceride and high-density lipoprotein.

DR, diabetic retinopathy; eGFR, estimated glomerular filtration rate; HR, hazard ratio; NA, not applicable; STDR, sight-threatening diabetic retinopathy. 

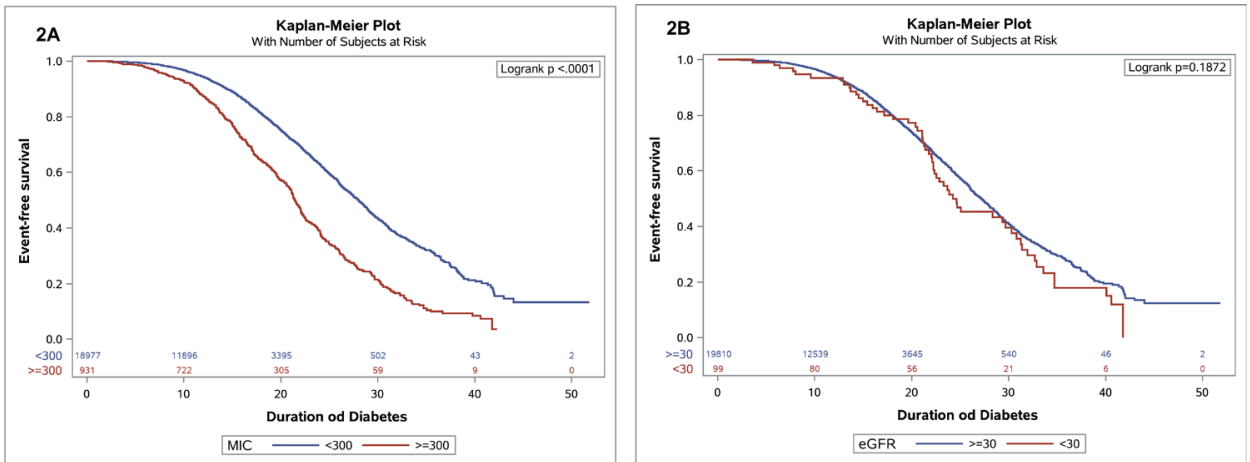

Figure 2 Kaplan-Meier curve. Cumulative risk for the development of sight-threatening diabetic retinopathy (STDR). Risk (survival plot) measured with albuminuria $\geq 300 \mu \mathrm{g} / \mathrm{mg}(\mathrm{A})$ and estimated glomerular filtration rate $(\mathrm{eGFR})<30 \mathrm{~mL} / \mathrm{min} / 1.73 \mathrm{~m}{ }^{2}$ (B). The $y$ axis shows the cumulative risk to develop new-onset STDR and the $x$ axis shows the duration of diabetes (years). The red curve represents the effect of patients with albuminuria $\geq 300 \mu \mathrm{g} / \mathrm{mg}$ and eGFR $<30 \mathrm{~mL} / \mathrm{min} / 1.73 \mathrm{~m}^{2}$ as risk factor, and the blue curve patients with albuminuria $<300 \mu \mathrm{g} / \mathrm{mg}$ and eGFR $>30 \mathrm{~mL} / \mathrm{min} / 1.73 \mathrm{~m}^{2}$. MIC, macroalbuminuria.

STDR and DKD and specifically on the value of DKD as a predictor for the development of DR and progression to STDR.

A number of factors contribute to both renal and retinal microangiopathies; these include age at onset of diabetes, duration of diabetes, HbAlc level, hypertension and dyslipidemia. ${ }^{4582425}$ Vascular endothelial growth factor (VEGF) production is induced in response to ischemia or hypoxia and its expression is involved in the pathogenesis of DR as well as DKD. ${ }^{26}$ VEGF is an important factor in the development of STDR (both PDR and DME) due to alterations caused by VEGF on the retinal capillaries. Drugs targeting VEGF (anti-VEGF agents) are being used successfully in the treatment of $\mathrm{DME}^{27}$ and more recently in the treatment of PDR as well. ${ }^{28}$ Patients with chronic kidney disease (CKD) have been shown to have elevated serum VEGF, and this inversely correlates with eGFR. ${ }^{29}$ This could possibly explain why the abnormal renal profiles correlated well with new-onset STDR in our study.

The strong correlation of baseline renal profile (serum creatinine, eGFR and albuminuria) with the development of new-onset DR and STDR suggests that DKD can predict the development of STDR. Our study has shown that both progressive decrease in eGFR $<60 \mathrm{~mL} / \mathrm{min} / 1.73 \mathrm{~m}^{2}$ and presence of albuminuria $(\geq 30 \mu \mathrm{g} / \mathrm{mg})$ at baseline significantly increased the risk for progression to STDR during the follow-up. Patients with severely diminished eGFR $<30 \mathrm{~mL} / \mathrm{min} / 1.73 \mathrm{~m}^{2}$ had four times higher risk of development of new-onset DR and five times greater risk for progression to STDR when compared with those with eGFR $>90 \mathrm{~mL} / \mathrm{min} / 1.73 \mathrm{~m}^{2}$. Patients with macroalbuminuria $(\geq 300 \mu \mathrm{g} / \mathrm{mg})$ had twofold higher hazard of DR and threefold higher risk for progression to STDR when compared with those with normoalbuminuria.

The association between CKD and DR has been investigated earlier in various cross-sectional studies in India. ${ }^{56}$ Microalbuminuria has been found to be a reliable marker of DR in these epidemiological studies. ${ }^{56}$ In the Chennai Urban Rural Epidemiology Study, nephropathy increased the odds for developing DR by 2.4 times, and the risk for nephropathy $(\mathrm{OR}=5.3, \mathrm{p}<0.001)$ and neuropathy $(\mathrm{OR}=2.9, \mathrm{p}<0.001)$ was significantly higher among the participants with STDR compared with those without DR. ${ }^{5}$ In the Sankara Nethralaya Diabetic Retinopathy Epidemiology and Molecular Genetic Study, people with microalbuminuria had a twofold higher risk of DR compared with those without microalbuminuria, and this risk increased to six times in the presence of macroalbuminuria. ${ }^{6}$ These studies established the association between albuminuria and DR. However, there are no studies that have looked at the association of eGFR and STDR in India.

We found an inverse relationship between eGFR values and the increasing severity of DR (no DR, NPDR and PDR) seen at baseline similar to that in the cross-sectional study done by Kaewput $e t a l^{15}$ as well as in a longitudinal study done by Hsieh et al. ${ }^{30}$ Similar to these two studies, our T2D patients with DR (NPDR and PDR/STDR) also had higher serum creatinine, higher microalbuminuria and lower eGFR level at baseline, when compared with those without DR.

Earlier cross-sectional studies that have assessed the association of both eGFR and microalbuminuria with DR have shown broadly similar results. In the crosssectional study by Rodríguez-Poncelas $e t a l^{31}$ in over 28000 patients in Spain, it was observed that eGFR levels $<45 \mathrm{~mL} / \mathrm{min} / 1.73 \mathrm{~m}^{2}$ were associated with higher DR prevalence. However, the study also showed that individuals with elevated UACR had a higher prevalence of DR than those with decreased eGFR. Lu et $a l^{32}$ and $\mathrm{Wu}$ et $a l^{33}$ showed that decrease in eGFR significantly correlated with DR, even after adjusting for age, gender and other covariates including albuminuria. Our results are similar to the results of the longitudinal study published by Hsieh et $a l^{30}$ which demonstrated a strong association of abnormal renal profiles with new-onset PDR, as well as the study done by Jeng $e a^{34}$ in another Asian population with T2D which showed DKD as an independent risk factor for the development 
and progression of DR. Hsieh $e t a l^{30}$ showed the association between lower eGFR and PDR and UACR with DME. However, Jeng et $a l^{34}$ did not find any association between DKD and DME. Our study showed an association of low eGFR with new-onset DR and STDR. Follow-up studies done by Chen $e t a l^{35}$ in Taipei and Romero-Aroca $e t a l^{36}$ in Spain have shown that microalbuminuria has a greater impact on predicting the development and progression of DR compared with eGFR, although both are important risk factors for DR. The Kaplan-Meier plots also demonstrated the increase in the accumulated risk of progression to STDR with increase in the duration of diabetes in patients with UACR $\geq 300 \mu \mathrm{g} / \mathrm{mg}$.

In a recently published longitudinal study by Yamanouchi $e t a l^{37}$ in 232 patients with T2D in Japan, they found that the severity of DR correlated with changes in renal pathology and was a predictor of biopsy-proven DKD and end-stage kidney disease. Their findings showed that screening for DR could be a tool in prognosticating the clinical course for DKD. DR and DKD have a common pathogenesis, and hence the progression of one microvascular complication has been associated with the progression of the other microvascular complication of diabetes. This is seen in our study too.

Zhu $e t a l^{38}$ recently published the prevalence and association of visual impairment and major eye diseases among 5518 participants with CKD from the National Health and Nutrition Examination Survey data. This cross-sectional study has shown the association between CKD and various eye disorders in participants with and without diabetes. Our study is a longitudinal follow-up study that has shown the role of DKD in the development of DR and progression to STDR.

Landmark randomized, multicenter, controlled clinical trials like the UK Prospective Diabetes Study (UKPDS) have shown that intensive treatment with strict glycemic control could decrease complications in people with T2D. ${ }^{39}$ Intensive glycemic control with a target $\mathrm{HbAlc}$ of $7 \%$ was associated with a significant $25 \%$ risk reduction in microvascular end points (both nephropathy and retinopathy) $(\mathrm{p}<0.01)$ compared with those in the conventional treatment group. Whether aggressive treatment of DKD at the early stages with strict glycemic and blood pressure control would help in the prevention of progression of DR to STDR would need to be assessed.

The regular point of care for people with T2D is the physician/diabetology clinic. Individuals with T2D are often asymptomatic and may not have any visual symptoms related to DR. Hence, they may not visit the ophthalmologist for regular retinal screening unless it is advised and emphasized by the diabetologist/physician. The eGFR values can be used by physicians for monitoring patients without DR and particularly those with DR without STDR. Frequent retinal examination screening and referrals can be suitably advised by the diabetologist based on the eGFR values, with special focus on those with eGFR levels $<60 \mathrm{~mL} / \mathrm{min} / 1.73 \mathrm{~m}^{2}$, as these individuals are at greater risk for new-onset DR as well as progression to STDR. Timely referral to retinal specialists for further management could help in preventing visual impairment and blindness due to STDR. ${ }^{40}$

\section{Strengths of the study}

To our knowledge, our study is possibly the first longitudinal study on a large sample from India that has provided a detailed analysis of the two important markers of renal function, eGFR and albuminuria, as suggested by the KDIGO guidelines. Since Asian Indians tend to get T2D at an earlier age and at lower body weights, data on the progression to complications are important. This is particularly relevant in the light of the different clusters of T2D proposed by Ahlqvist et $a t^{41}$ from Scandinavia where different subtypes were shown to be more prone to DR and DKD, respectively. Cox regression analysis to calculate the HR and assess the association of dynamic renal biomarkers with new-onset DR and risk for progression to STDR was performed based on all KDIGO categories. Our study suggests that eGFR level can be used by physicians as a marker to refer patients to the ophthalmologist.

\section{Limitations}

This is a clinic-based study and hence all the findings cannot be extrapolated to the general population. The analysis is retrospective, so the mean follow-up periods for patients with T2D have been variable. However, this is likely to be the case in the real-world scenario.

\section{CONCLUSION}

Abnormal renal parameters, especially diminished eGFR at baseline and albuminuria, increased the risk of development of new-onset DR as well as progression to STDR. In low-income and middle-income countries like India, where there is no nationwide DR screening program $^{42}$ and DR screening is more opportunistic, the eGFR values and/or albuminuria can possibly be used by physicians for monitoring patients to enable timely referral to the ophthalmologist for prompt management of STDR.

\section{Author affiliations}

${ }^{1}$ Ophthalmology, Madras Diabetes Research Foundation and Dr. Mohan's Diabetes Specialities Centre, Chennai, Tamil Nadu, India

${ }^{2}$ Epidemiology, Madras Diabetes Research Foundation, Chennai, Tamil Nadu, India ${ }^{3}$ Biostatistics, Madras Diabetes Research Foundation, Chennai, Tamil Nadu, India ${ }^{4}$ Diabetology, Madras Diabetes Research Foundation and Dr. Mohan's Diabetes Specialities Centre, Chennai, Tamil Nadu, India

${ }^{5}$ Data Management, Madras Diabetes Research Foundation, Chennai, Tamil Nadu, India

${ }^{6}$ University College London, London, UK

${ }^{7}$ NIHR Moorfields Biomedical Research Centre, Moorfields Eye Hospital NHS

Foundation Trust, London, UK

${ }^{8}$ Vitreo-Retina Services, Vision Research Foundation, Chennai, Tamil Nadu, India 
Contributors Conceived and designed the study: RRaj, SS, VM. Wrote the manuscript: RRaj, CSSR. Data retrieval: SJR. Data cleansing and analysis: GU, CSSR. Statistical analysis: UV. Helped in revising the manuscript for important intellectual content: VM, RU, RMA, SS, RRN. Read and approved the final manuscript: RRaj, CSSR, UV, GU, SJR, RU, RMA, SS, RRN, VM.

Funding This study, within the ORNATE India project, was funded by the Global Challenges Research Fund (GCRF) UK Research and Innovation (UKRI) (MR/ P207881/1). The research was supported by the NIHR Biomedical Research Centre at Moorfields Eye Hospital NHS Foundation Trust.

Competing interests None declared.

Patient consent for publication Not required.

Ethics approval This study was approved by the Institutional Ethical Committee of Madras Diabetes Research Foundation (Reg No ECR/194/Inst/TN/2013/RR-16).

Provenance and peer review Not commissioned; externally peer reviewed.

Data availability statement All data relevant to the study are included in the article or uploaded as supplementary information. Additional data are available upon reasonable request.

Open access This is an open access article distributed in accordance with the Creative Commons Attribution Non Commercial (CC BY-NC 4.0) license, which permits others to distribute, remix, adapt, build upon this work non-commercially, and license their derivative works on different terms, provided the original work is properly cited, appropriate credit is given, any changes made indicated, and the use is non-commercial. See: http://creativecommons.org/licenses/by-nc/4.0/.

ORCID iDs

Ramachandran Rajalakshmi http://orcid.org/0000-0002-7063-6026

Ranjit Mohan Anjana http://orcid.org/0000-0002-4843-1374

Viswanathan Mohan http://orcid.org/0000-0001-5038-6210

\section{REFERENCES}

1 Anjana RM, Pradeepa R, Deepa M, et al. Prevalence of diabetes and prediabetes (impaired fasting glucose and/or impaired glucose tolerance) in urban and rural India: phase I results of the Indian Council of medical Research-INdia diabetes (ICMR-INDIAB) study. Diabetologia 2011;54:3022-7.

2 International Diabetes Federation. Diabetes atlas. 9 edn. Brussels, Belgium: International Diabetes Federation, 2019. http://www. diabetesatlas.org

3 Rema M, Premkumar S, Anitha B, et al. Prevalence of diabetic retinopathy in urban India: the Chennai urban rural epidemiology study (cures) eye study, I. Invest Ophthalmol Vis Sci 2005;46:2328-33.

4 Unnikrishnan RI, Rema M, Pradeepa R, et al. Prevalence and risk factors of diabetic nephropathy in an urban South Indian population: the Chennai urban rural epidemiology study (cures 45). Diabetes Care 2007;30:2019-24.

5 Pradeepa R, Anitha B, Mohan V, et al. Risk factors for diabetic retinopathy in a South Indian Type 2 diabetic population--the Chennai Urban Rural Epidemiology Study (CURES) Eye Study 4. Diabet Med 2008;25:536-42.

6 Raman R, Rani PK, Reddi Rachepalle S, Rachepalle SR, et al. Prevalence of diabetic retinopathy in India: Sankara Nethralaya diabetic retinopathy epidemiology and molecular genetics study report 2. Ophthalmology 2009;116:311-8.

7 Fong DS, Ferris FL, Davis MD, et al. Causes of severe visual loss in the early treatment diabetic retinopathy study: ETDRS report No. 24 Am J Ophthalmol 1999;127:137-41.

8 Yau JWY, Rogers SL, Kawasaki R, et al. Global prevalence and major risk factors of diabetic retinopathy. Diabetes Care 2012;35:556-64.

9 Rajalakshmi R, Prathiba V, Mohan V. Does tight control of systemic factors help in the management of diabetic retinopathy? Indian J Ophthalmol 2016;64:62

10 Klein R, Klein BE, Moss SE, et al. The Wisconsin epidemiologic study of diabetic retinopathy. II. prevalence and risk of diabetic retinopathy when age at diagnosis is less than 30 years. Arch Ophthalmol 1984;102:520-6.

11 Klein R, Klein BE, Moss SE, et al. The Wisconsin epidemiologic study of diabetic retinopathy. III. prevalence and risk of diabetic retinopathy when age at diagnosis is 30 or more years. Arch Ophthalmol 1984;102:527-32.

12 Rajalakshmi R, Amutha A, Ranjani $\mathrm{H}$, et al. Prevalence and risk factors for diabetic retinopathy in Asian Indians with young onset type 1 and type 2 diabetes. J Diabetes Complications 2014;28:291-7.

13 Stratton IM, Kohner EM, Aldington SJ, et al. UKPDS 50: risk factors for incidence and progression of retinopathy in type II diabetes over 6 years from diagnosis. Diabetologia 2001;44:156-63.

$14 \mathrm{He} \mathrm{F}$, Xia X, Wu XF, et al. Diabetic retinopathy in predicting diabetic nephropathy in patients with type 2 diabetes and renal disease: a meta-analysis. Diabetologia 2013;56:457-66.

15 Kaewput W, Thongprayoon C, Rangsin R, et al. Associations of renal function with diabetic retinopathy and visual impairment in type 2 diabetes: a multicenter nationwide cross-sectional study. World $\mathrm{J}$ Nephrol 2019:8:33-43.

16 Kidney Disease: Improving Global Outcomes Chronic Kidney Disease Guideline Development Work Group Members. Evaluation and management of chronic kidney disease: synopsis of the kidney disease: improving global outcomes 2012 clinical practice guideline. Ann Intern Med 2013;158:825-30.

17 American Diabetes Association. Diagnosis and classification of diabetes mellitus. Diabetes Care 2014;37:S81-90.

18 Chobanian AV, Bakris GL, Black HR, et al. The seventh report of the joint National Committee on prevention, detection, evaluation, and treatment of high blood pressure: the JNC 7 report. JAMA 2003;289:2560-72.

19 Jayashri R, Venkatesan U, Rohan M, et al. Prevalence of vitamin $\mathrm{B}_{12}$ deficiency in South Indians with different grades of glucose tolerance. Acta Diabetol 2018;55:1283-93.

20 Grading diabetic retinopathy from stereoscopic color fundus photographs--an extension of the modified Airlie House classification. ETDRS report number 10. Early Treatment Diabetic Retinopathy Study Research Group. Ophthalmology 1991:98:786-806.

21 Rajalakshmi R, Arulmalar S, Usha M, et al. Validation of smartphone based retinal photography for diabetic retinopathy screening. PLoS One 2015;10:e0138285

22 Wilkinson CP, Ferris FL, Klein RE, et al. Proposed International clinical diabetic retinopathy and diabetic macular edema disease severity scales. Ophthalmology 2003;110:1677-82.

23 Stevens LA, Schmid CH, Greene T, et al. Comparative performance of the CKD epidemiology collaboration (CKD-EPI) and the modification of diet in renal disease (MDRD) study equations for estimating GFR levels above $60 \mathrm{~mL} / \mathrm{min} / 1.73 \mathrm{M} 2$. Am J Kidney Dis 2010;56:486-95.

24 Mohan V, Meera R, Premalatha G, et al. Frequency of proteinuria in type 2 diabetes mellitus seen at a diabetes centre in southern India. Postgrad Med J 2000;76:569-73.

25 Harris Nwanyanwu K, Talwar N, Gardner TW, et al. Predicting development of proliferative diabetic retinopathy. Diabetes Care 2013;36:1562-8.

26 Gupta N, Mansoor S, Sharma A, et al. Diabetic retinopathy and VEGF. Open Ophthalmol J 2013;7:4-10.

27 Diabetic Retinopathy Clinical Research Network, Elman MJ, Qin $\mathrm{H}$, et al. Intravitreal ranibizumab for diabetic macular edema with prompt versus deferred laser treatment: three-year randomized trial results. Ophthalmology 2012:119:2312-8.

28 Beaulieu WT, Bressler NM, Melia M, et al. Panretinal photocoagulation versus ranibizumab for proliferative diabetic retinopathy: patient-centered outcomes from a randomized clinical trial. Am J Ophthalmol 2016;170:206-13.

29 Pawlak K, Mysliwiec M, Pawlak D. Oxidative stress, phosphate and creatinine levels are independently associated with vascular endothelial growth factor levels in patients with chronic renal failure. Cytokine 2008:43:98-101.

30 Hsieh Y-T, Tsai M-J, Tu S-T, et al. Association of abnormal renal profiles and proliferative diabetic retinopathy and diabetic macular edema in an Asian population with type 2 diabetes. JAMA Ophthalmol 2018;136:68-74.

31 Rodríguez-Poncelas A, Mundet-Tudurí X, Miravet-Jiménez S, et al. Chronic kidney disease and diabetic retinopathy in patients with type 2 diabetes. PLoS One 2016;11:e0149448.

32 Lu B, Song X, Dong X, et al. High prevalence of chronic kidney disease in population-based patients diagnosed with type 2 diabetes in downtown Shanghai. J Diabetes Complications 2008;22:96-103.

$33 \mathrm{Wu}$ J, Geng J, Liu L, et al. The relationship between estimated glomerular filtration rate and diabetic retinopathy. J Ophthalmol 2015;2015:1-8

34 Jeng C-J, Hsieh Y-T, Yang C-M, et al. Diabetic retinopathy in patients with diabetic nephropathy: development and progression. PLOS One 2016;11:e0161897.

35 Chen Y-H, Chen H-S, Tarng D-C. More impact of microalbuminuria on retinopathy than moderately reduced GFR among type 2 diabetic patients. Diabetes Care 2012;35:803-8. 
36 Romero-Aroca P, Baget-Bernaldiz M, Navarro-Gil R, et al. Glomerular filtration rate and/or ratio of urine albumin to creatinine as markers for diabetic retinopathy: a ten-year follow-up study. J Diabetes Res 2018;2018:1-9.

37 Yamanouchi M, Mori M, Hoshino J, et al. Retinopathy progression and the risk of end-stage kidney disease: results from a longitudinal Japanese cohort of 232 patients with type 2 diabetes and biopsyproven diabetic kidney disease. BMJ Open Diabetes Res Care 2019;7:e000726.

38 Zhu Z, Liao H, Wang W, et al. Visual impairment and major eye diseases in chronic kidney disease: the National health and nutrition examination survey, 2005-2008. Am J Ophthalmol 2020;213:24-33.
39 King P, Peacock I, Donnelly R. The UK prospective diabetes study (UKPDS): clinical and therapeutic implications for type 2 diabetes. $\mathrm{Br}$ J Clin Pharmacol 1999;48:643-8.

40 Fong DS, Ferris FL, Davis MD, et al. Causes of severe visual loss in the early treatment diabetic retinopathy study: ETDRS report No. 24 early treatment diabetic retinopathy study Research Group. Am J Ophthalmol 1999;127:137-41.

41 Ahlqvist E, Storm P, Käräjämäki A, et al. Novel subgroups of adult-onset diabetes and their association with outcomes: a datadriven cluster analysis of six variables. Lancet Diabetes Endocrinol 2018;6:361-9.

42 Namperumalsamy P, Nirmalan PK, Ramasamy K. Developing a screening program to detect sight-threatening diabetic retinopathy in South India. Diabetes Care 2003;26:1831-5. 